$$
\begin{aligned}
& \text { ANL/ED/CP }-91100 \\
& \text { CONF- } 960811-2
\end{aligned}
$$

\title{
Calculation of Vacancy Wind Contributions in Ternary Diffusion*
}

\author{
By \\ M. C. Petri \\ Argonne National Laboratory \\ 9700 South Cass Avenue \\ Argonne, Illinois 60439 \\ USA \\ and \\ M. A. Dayananda \\ Purdue University \\ School of Materials Engineering \\ West Lafayette, IN, 47907 \\ USA
}

$\angle F C E I V E D$

SFP 191996

OSTI

August 1996

Conference Proceedings

DIMAT 96-International Conference

on Diffusion in Materials

The submitted manuscript has been authored
by a contractor of the U.S. Government under
contract No. W-31-109-ENG-38. Accordingly,
the U. S. Government retains a nonexclusive,
royalty-free license to publish or reproduce the
published form of this contribution or allow
others to do so, for U. S. Government
purposes.

DISTRBUTION OF THS DOCUMENT IS UNMITES

*Work supported by the U.S. Department of Energy, Reactor Systems,

Development and Technology, under Contract No. W-31-109-ENG-38. 
DISCLAIMER

Portions of this document may be illegible in electronic image products. Images are produced from the best available original document. 


\section{DISCLAIMER}

This report was prepared as an account of work sponsored by an agency of the United States Government. Neither the United States Government nor any agency thereof, nor any of their employees, makes any warranty, express or implied, or assumes any legal liability or responsibility for the accuracy, completeness, or usefulness of any information, apparatus, product, or process disclosed, or represents that its use would not infringe privately owned rights. Reference herein to any specific commercial product, process, or service by trade name, trademark, manufacturer, or otherwise does not necessarily constitute or imply its endorsement, recommendation, or favoring by the United States Government or any agency thereof. The views and opinions of authors expressed herein do not necessarily state or reflect those of the United States Government or any agency thereof. 


\title{
CALCULATION OF VACANCY WIND CONTRIBUTIONS IN TERNARY DIFFUSION
}

\author{
M. C. Petri ${ }^{1}$ and M. A. Dayananda ${ }^{2}$ \\ 'Argonne National Laboratory, 9700 S. Cass Ave., Argonne, IL 60439, USA \\ ${ }^{2}$ School of Materials Engineering, Purdue University, West Lafayette, IN 47907, USA
}

Keywords: intrinsic diffusion, vacancy wind effect, U-Pu-Zr alloys, atomic mobility

\begin{abstract}
In the absence of kinetic cross interactions between diffusing components, intrinsic diffusion can be described by a simple atomic mobility model. For systems where the diffusional interactions among components cannot be ignored, the interactions can be related to a vacancy wind effect in which the intrinsic flux of a component is influenced by the net vacancy flux. Atomic mobilities are calculated at selected composition points on the diffusion paths of $\gamma$-phase U-Pu-Zr diffusion couples investigated at $750^{\circ} \mathrm{C}$ to assess the contribution by the vacancy wind effect to the intrinsic diffusion of the individual components. The results point to the possibility that a large vacancy wind contribution may cause a component to diffuse intrinsically up its own chemical potential gradient.
\end{abstract}

\section{INTRODUCTION}

Manning [1] expressed the kinetic interactions among components in terms of a vacancy wind effect by which a component's intrinsic flux is influenced by the net vacancy flux. An atom intrinsically diffusing in a direction opposite to the net vacancy flow is more likely to encounter and interchange with a vacancy. Thus, the vacancy wind effect can enhance atom flows opposite to the net vacancy flux, while atom flows in the same direction as the vacancy flux are retarded. Manning accounted for the vacancy wind effect by adding a term, $\left(\frac{J_{i}}{\rho}\right)_{v}$, to Darken's simple atomic mobility model [2]:

$$
\begin{aligned}
\frac{J_{i}}{\rho} & =\left(\frac{J_{i}}{\rho}\right)_{o}+\left(\frac{J_{i}}{\rho}\right)_{v} \\
& =-N_{i} \beta_{i}\left(\frac{\partial \mu_{i}}{\partial x}\right)_{i}-\alpha N_{i} \beta_{i}\left(\frac{J_{v}}{\rho}\right) \quad(i=1,2, \ldots, n),
\end{aligned}
$$

where $N_{i}$ is the atom fraction of component $i, \beta_{i}$ is the atomic mobility, and $\alpha$ is a vacancy wind parameter that relates the effect of the vacancy flux $J_{v}$ on the intrinsic flux $J_{i}$. Although there is a single vacancy wind parameter for all components, $\alpha$ depends on composition. Based on Eq. 2 , a vacancy flux with the same sign as the chemical potential gradient $\left(\frac{\partial \mu_{i}}{\partial x}\right)$ enhances the intrinsic flux. For a small chemical potential gradient, the vacancy wind may make a large relative contribution to the intrinsic flux, depending on the magnitudes of $J_{v}$ and $\alpha$. Expressions 
for $\alpha$ in terms of intrinsic fluxes and atomic mobilities have been derived and applied to ternary systems. [3, 4] The atomic mobility parameters $\beta_{i}$ and $\alpha$ can also be related to interdiffusion fluxes. [5]

\section{DIFFUSION COUPLE EXPERIMENTS}

Eight diffusion couple experiments were conducted with alloys selected from the uraniumrich corner of the U-Pu-Zr ternary phase diagram. The couples are listed in Table 1. All couples were annealed for 16.5 hours at $750^{\circ} \mathrm{C}$ in a highpurity helium atmosphere. At this temperature all alloys are in the bcc $\gamma$-U phase field, except for the pure uranium sample, which is in the tetragonal $\beta-U$ phase region. Details of the experimental procedures and diffusion coefficient calculations have been presented elsewhere. [6]

Fig. 1 presents the diffusion paths for six of the eight experiments and includes the Matano and marker plane compositions. (Diffusion paths for Couples 1 and 4, the replicates of Couples 2 and 5 , are not shown to reduce confusion among similar plots.) Heumann's method [7] was used to calculate intrinsic fluxes for the marker plane compositions and chemical potential gradients were calculated from a thermodynamic model of the U-Pu-Zr system. [5]

\section{CALCULATION OF $\beta_{i}$ AND $\alpha$ FROM INTRINSIC DIFFUSION FLUXES}

Eq. 2 contains $n$ mobility variables plus a vacancy wind parameter. Therefore, two independent diffusion couples are needed to solve the $n+1$ unknowns. These couples must have marker planes with the same composition. This is not the case in the U-Pu$\mathrm{Zr}$ diffusion couples (Fig. 1). Nevertheless, $\boldsymbol{\beta}_{i}$ and $\alpha$ can be calculated assuming that they are constant over a limited composition range.

The marker motion observed in Couples 4 and 5 was negligible and, hence, the vacancy wind effect can be ignored.

Therefore, Eq. 2 can be solved for the $\beta_{i}$ values at the marker plane without invoking the
Table 1. Diffusion Couples Annealed at $750^{\circ} \mathrm{C}$ for 16.5 Hours

\begin{tabular}{|c|l|}
\hline Couple & \multicolumn{1}{|c|}{ Diffusion Couple Alloys } \\
\hline $1,2^{(2)}$ & U-20Zr vs. U-22Pu-3Zr ${ }^{(b)}$ \\
\hline 3 & $\mathrm{U}-20 Z r$ vs. U-22Pu-20Zr \\
\hline $4,5^{(a)}$ & $\mathrm{U}$ vs. U-22Pu-20Zr \\
\hline 6 & $\mathrm{U}-22 \mathrm{Pu}-3 \mathrm{Zr}$ vs. U-22Pu-20Zr \\
\hline 7 & $\mathrm{U} v s . \mathrm{U}-22 \mathrm{Pu}-3 \mathrm{Zr}$ \\
\hline 8 & $\mathrm{U} v s . \mathrm{U}-20 \mathrm{Zr}$ \\
\hline
\end{tabular}

(a) Couples 1 and 2 and Couples 4 and 5 are duplicate couples.

(b) All concentrations are atomic percentages.

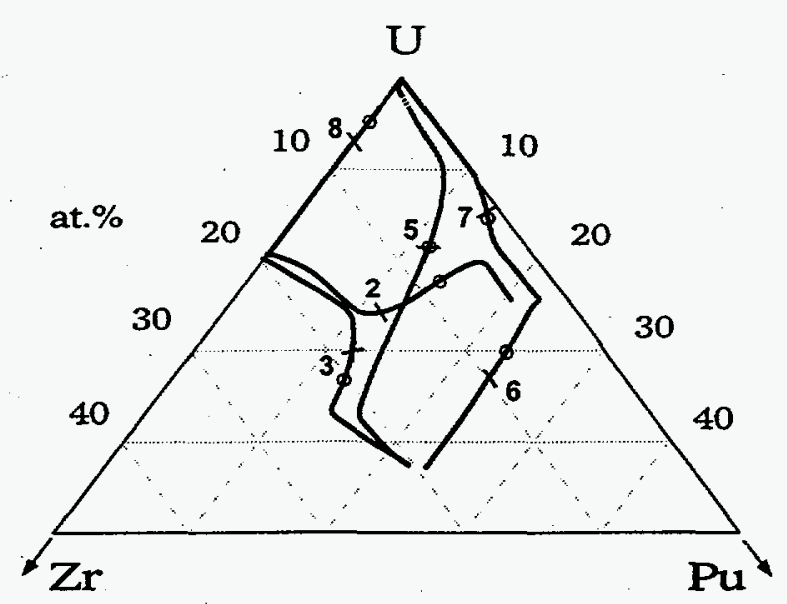

Fig. 1. Experimental diffusion paths at $750^{\circ} \mathrm{C}$ with the compositions of the Matano ( 1 ) and marker (o) planes. Couples 1 and 4 (not shown) are replicates of Couples 2 and 5. [6] 
vacancy wind term. These couples provide no information about the vacancy wind parameter, however. Couples 1 and 2, on the other hand, exhibit a large marker motion. By applying an average set of mobilities from Couple 5 to the Couple 2 marker plane, one can determine the vacancy wind parameter. This $\alpha$ value can then be applied back to the Couple 5 marker plane using Eq. 2 to modify the original $\beta_{i}$ estimates. Iterating in this manner produces a $\beta_{\mathrm{Zr}}$ of $2.5 \cdot 10^{7}$ $\mathrm{m} / \mathrm{N} \cdot \mathrm{s}$, a $\beta_{\mathrm{U}}$ of $5.7 \cdot 10^{7} \mathrm{~m} / \mathrm{N} \cdot \mathrm{s}$, a $\beta_{\mathrm{Pu}}$ of $9.5 \cdot 10^{7} \mathrm{~m} / \mathrm{N} \cdot \mathrm{s}$, and an $\alpha$ of $15.5 \cdot 10^{-9} \mathrm{~N} \cdot \mathrm{s} / \mathrm{m}$. The ratio of atomic mobilities $\beta_{\mathrm{Zr}}: \beta_{\mathrm{U}}: \beta_{\mathrm{Pu}}$ is approximately $1: 2: 4$.

\section{THE VACANCY WIND CONTRIBUTION TO INTRINSIC DIFFUSION}

Although the vacancy wind parameter $\alpha$ may decrease slightly with increasing plutonium concentration [5], Eq. 2 can be used to calculate atomic mobilities at marker planes for a given value of $\alpha$. For selected couples, Table 2 provides a comparison of mobilities calculated with a value of $15.5 \cdot 10^{-9} \mathrm{~N} \cdot \mathrm{s} / \mathrm{m}$ for $\alpha$ with those determined for $\alpha=0$ (the simple atomic mobility model). These calculations show that the introduction of a vacancy wind parameter in the atomic mobility calculations yields $\beta_{i}$ values that vary little from one marker plane composition to another for all the couples. The Pu mobility is consistently greater than the U mobility, which in turn is greater than the $\mathrm{Zr}$ mobility. This conclusion cannot be drawn from the simple atomic mobility model, which ignores the vacancy wind effect.

\section{Table 2. Calculated Atomic Mobilities Using a Presumed Vacancy Wind Parameter}

\begin{tabular}{|c|c|c|c|c|c|c|c|}
\hline \multirow{2}{*}{ Couple } & \multirow{2}{*}{ Element } & $\begin{array}{c}\text { Marker Plane } \\
\text { Composition } \\
(\text { at.\%) }\end{array}$ & $\begin{array}{c}\beta_{i}^{(a)} \\
(\alpha=0)\end{array}$ & $\beta_{i}^{(b)}$ & $\left(\frac{J_{i}}{\rho}\right)_{0}$ & $\left(\frac{J_{i}}{\rho}\right)_{v}$ & $\left(\frac{J_{i}}{\rho}\right)^{(c)}$ \\
\cline { 3 - 9 } & & & $\left(10^{7} \frac{\mathrm{m}}{\mathrm{N} \cdot \mathrm{s}}\right)$ & \multicolumn{3}{|c|}{$\left(10^{-6}\right.$ at. fraction $\left.\cdot \mu \mathrm{m} / \mathrm{s}\right)$} \\
\hline \multirow{3}{*}{2} & $\mathrm{Zr}$ & 8 & - & - & - & - & - \\
& $\mathrm{U}$ & 78 & 294 & 5.4 & 17 & 888 & 905 \\
& $\mathrm{Pu}$ & 14 & 26 & 9.4 & 160 & 287 & 446 \\
\hline \multirow{3}{*}{3} & $\mathrm{Zr}$ & 20 & - & - & - & - & - \\
& $\mathrm{U}$ & 67 & -4.0 & 7.3 & 232 & -359 & -127 \\
& $\mathrm{Pu}$ & 13 & 11 & 8.6 & -266 & -81 & -347 \\
\hline \multirow{3}{*}{5} & $\mathrm{Zr}$ & 6 & 2.4 & 2.4 & -90 & 0.3 & -90 \\
& $\mathrm{U}$ & 82 & 5.8 & 5.7 & 377 & 8 & 385 \\
& $\mathrm{Pu}$ & 12 & 9.5 & 9.5 & -286 & 1.8 & -284 \\
\hline
\end{tabular}

${ }^{(a)}$ The simple atomic mobility is based on a vacancy wind parameter $(\alpha)$ of zero.

(b) The atomic mobility is calculated for $\alpha=15.5 \cdot 10^{-9} \frac{\mathrm{N} \cdot \mathrm{s}}{\mathrm{m}}$.

${ }^{(c)}$ See equation 1.

Table 2 also includes a breakdown of the chemical potential gradient and vacancy wind contributions to the intrinsic fluxes as described by Eq. 1. For Couple 2 the large vacancy wind 
contribution provides a driving force for intrinsic diffusion of $U$ in the same direction as its chemical potential gradient. For Couple 3, however, the magnitude of the vacancy wind

contribution $\left(\frac{J_{i}}{\rho}\right)_{\nu}$ to the intrinsic flux of $U$ is larger than $\left(\frac{J_{j}}{\rho}\right)_{o}$ due to the chemical potential gradient, but in the opposite direction. Although the vacancy wind parameter is expected to have a small composition dependence, $\alpha$ was presumed to be a constant $15.5 \cdot 10^{-9}$ $\mathrm{N} \cdot \mathrm{s} / \mathrm{m}$ in these calculations. Nevertheless, any $\alpha$ value greater than $10.0 \cdot 10^{-9} \mathrm{~N} \cdot \mathrm{s} / \mathrm{m}$ would still yield a larger vacancy wind contribution than the chemical potential gradient contribution for $U$ in Couple 3. Furthermore, the calculated mobility for uranium $\left(7.3 \cdot 10^{7} \mathrm{~m} / \mathrm{N} \cdot \mathrm{s}\right)$ based on an $\alpha$ value of $15.5 \cdot 10^{-9} \mathrm{~N} \cdot \mathrm{s} / \mathrm{m}$ is consistent with the mobilities calculated throughout the U-Pu-Zr system, which were approximately constant regardless of the relative contribution of the vacancy wind effect to the intrinsic flux. Detailed results will be presented in a forthcoming paper. [5]

The larger contribution to the uranium intrinsic flux by $\left(\frac{J_{i}}{\rho}\right)_{v}$ relative to that by $\left(\frac{J_{i}}{\rho}\right)_{o}$ in Couple 3 suggests that a component can be driven to intrinsically diffuse up its own chemical potential gradient, provided that the vacancy wind effect dominates. This observation arises within the assumptions used in the vacancy wind model.

\section{SUMMARY}

The atomic mobilities $\beta_{\mathrm{Pu}}, \beta_{\mathrm{U}}$, and $\beta_{\mathrm{zr}}$ were determined from relationships between the chemical potential gradients and the intrinsic fluxes for isothermal diffusion couple experiments with body-centered cubic U-Pu-Zr alloys. The ratio of $\beta_{\mathrm{Pu}}: \beta_{\mathrm{U}}: \beta_{\mathrm{Zr}}$ is approximately $4: 2: 1$ at $750^{\circ} \mathrm{C}$. The atomic mobilities can be treated as independent of composition with a vacancy wind parameter that has a small dependence on plutonium concentration. The vacancy wind contribution to intrinsic diffusion is appreciable and cannot be ignored in diffusion couples with large Kirkendall shifts.

\section{ACKNOWLEDGMENTS}

This work was supported by the U.S. Department of Energy, Reactor Systems, Development and Technology, under Contract No. W-31-109-ENG-38.

\section{REFERENCES}

[1] J. R. Manning, Metall. Trans., 1, 499 (1970).

[2] L. S. Darken, in Atom Movements, ASM, Cleveland, Ohio, 1951, 1.

[3] M. A. Dayananda, Metall. Trans., 2334 (1971).

[4] P. T. Carlson, M. A. Dayananda, and R. E. Grace, Metall. Trans. A, 6A, 1245 (1975).

[5] M. C. Petri and M. A. Dayananda, to be published.

[6] M. C. Petri and M. A. Dayananda, J. Nucl. Mater., to be published.

[7] T. Heumann, Z. Phys. Chem., 201, 168 (1952). 